\title{
Effectiveness of the Spinecor brace based on the new standardized criteria proposed by the Scoliosis Research Society for adolescent idiopathic scoliosis
}

\author{
Christine Coillard ${ }^{1,2}$, Valerie Vachon ${ }^{1,2}$, Alin Circo ${ }^{1,2}$, Marie Beauséjour ${ }^{1}$, \\ Nancy Shawafaty ${ }^{1}$ and Charles H Rivard*1,2
}

\author{
Address: ${ }^{1}$ Research Center, Sainte-Justine Hospital and University of Montreal, Canada. 3175 ch. Côte Ste-Catherine, Montréal, Québec, Canada, \\ H3T 1C5 and 2University of Montreal, Montreal, Canada \\ Email: Charles H Rivard* - chrivard@gmail.com \\ * Corresponding author
}

from 4th International Conference on Conservative Management of Spinal Deformities

Boston, MA, USA. 13-16 May 2007

Published: 12 October 2007

Scoliosis 2007, 2(Suppl I):S2I doi:|0.I|86/|748-7|6I-2-SI-S2I

This abstract is available from: http://www.scoliosisjournal.com/content/2/SI/S2 I

(c) 2007 Coillard et al; licensee BioMed Central Ltd.

\section{Objective}

To evaluate the effectiveness of the Dynamic SpineCor brace [1] for adolescent idiopathic scoliosis (AIS).

\section{Study design}

From 1993 to 2006, 493 patients were treated using the SpineCor brace. Of these patients, 249 subjects fitted the criteria for inclusion and seventy-nine were still actively being treated. Ultimately, 170 patients have a definitive outcome. Assessment of brace effectiveness included the following criteria: 1) percentage of patients who have five degrees (Cobb angle) or less curve progression and the percentage of patients who have six degrees or more progression; 2) percentage of patients for whom surgery was recommended or was carried out, before skeletal maturity; 3) percentage of patients with curves exceeding 45 degrees at maturity (end of treatment); and 4) two years' followup beyond maturity to determine the percentage of patients who subsequently underwent surgery.

\section{Results}

Successful treatment (correction $>5$ degrees or stabilization \pm 5 degrees) was achieved in 101 of the 170 patients $(59.4 \%)$ from the time of the fitting of the SpineCor brace to the point at which it was discontinued. Thirty-nine immature patients $(22.9 \%)$ required surgical fusion while receiving treatment. Two patients out of $170(1.2 \%)$ had curves exceeding 45 degrees at maturity.

\section{Conclusion}

The SpineCor brace is effective for the treatment of AIS. Moreover, positive outcomes for 45 patients out of 47 $(95.7 \%)$ treated with the SpineCor brace were maintained after two years.

\section{References}

I. Coillard C, Leroux MA, Badeaux J, Rivard CH: SPINECOR: a new therapeutic approach for idiopathic scoliosis. Stud Health Technol Inform 2002, 88:215-217. 